DOE Contract No. DE-AC21-93MC30010

RTI Project No. 93U-5666

January 1, 1999 to March 31, 1999

\title{
BENCH-SCALE DEMONSTRATION OF HOT-GAS DESULFURIZATION TECHNOLOGY
}

\author{
Quarterly Technical Progress Report
}

\author{
Submitted to \\ U.S. Department of Energy \\ Federal Energy Technology Center \\ 3610 Collins Ferry Road \\ P.O. Box 880 \\ Morgantown, WW 26507-0880
}


RTI Project No. 93U-5666

DOE Contract No. DE-AC21-93MC30010

January 1, 1999 to March 31, 1999

\section{BENCH-SCALE DEMONSTRATION OF HOT-GAS \\ DESULFURIZATION TECHNOLOGY}

Quarterly Technical Progress Report

Submitted to

U.S. Department of Energy

Federal Energy Technology Center 3610 Collins Ferry Road

P.O. Box 880

Morgantown, WW 26507-0880

Submitted by

Research Triangle Institute

P.O. Box 12194

Research Triangle Park, NC 27709

DOE COR:Thomas P. Dorchak RTI Project Manager:Santosh K. Gangwal RTI Project Engineer:Jeffrey W. Portzer 


\section{DISCLAIMER}

This report was prepared as an account of work sponsored by an agency of the United States Government. Neither the United States Government nor any agency thereof, nor any of their employees, make any warranty, express or implied, or assumes any legal liability or responsibility for the accuracy, completeness, or usefulness of any information, apparatus, product, or process disclosed, or represents that its use would not infringe privately owned rights. Reference herein to any specific commercial product, process, or service by trade name, trademark, manufacturer, or otherwise does not necessarily constitute or imply its endorsement, recommendation, or favoring by the United States Government or any agency thereof. The views and opinions of authors expressed herein do not necessarily state or reflect those of the United States Government or any agency thereof. 


\section{DISCLAIMER}

Portions of this document may be illegible in electronic image products. Images are produced from the best available original document. 


\section{TABLE OF CONTENTS}

Section

Page

1.0 Introduction and Summary $\ldots \ldots \ldots \ldots \ldots \ldots \ldots \ldots \ldots \ldots \ldots \ldots \ldots \ldots$

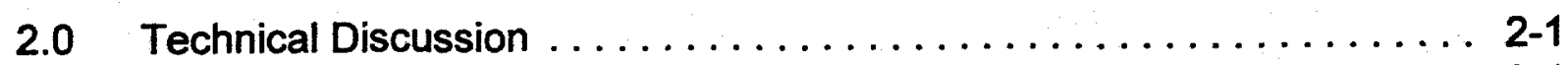

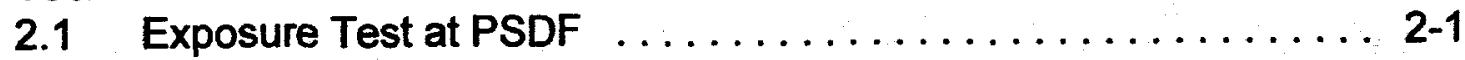

2.1 Bench-Scale Fluid-Bed Testing with $\mathrm{High}-\mathrm{SO}_{2}$ Concentration

Feed Streams ........................ 2-1

2.3 Slipstream Testing of the 6 X DSRP Unit at PSDF ........ 2-1

2.4 Technology Transfer / Commercialization ............. 2-2

3.0 Plans for Next Quarter .................... 


\section{List of Figures}

\section{Figure}

Page

1. Heater control panel being installed on DSRP equipment skid $\ldots \ldots \ldots 2-4$ 


\section{List of Tables}

Table

Page 


\subsection{INTRODUCTION AND SUMMARY}

The U.S. Department of Energy (DOE), Federal Energy Technology Center (FETC), is sponsoring research in advanced methods for controlling contaminants in hot coal gasifier gas (coal-derived fuel-gas) streams of integrated gasification combined-cycle (IGCC) power systems. The hot gas cleanup work seeks to eliminate the need for expensive heat recovery equipment, reduce efficiency losses due to quenching, and minimize wastewater treatment costs.

Hot-gas desulfurization research has focused on regenerable mixed-metal oxide sorbents that can reduce the sulfur in coal-derived fuel-gas to less than $20 \mathrm{ppmv}$ and can be regenerated in a cyclic manner with air for multicycle operation. Zinc titanate $\left.\left(\mathrm{Zn}_{2} \mathrm{TiO}_{4} \text { or } \mathrm{ZnTiO}\right)_{3}\right)$ formed by a solid-state reaction of zinc oxide $(\mathrm{ZnO})$ and titanium dioxide $\left(\mathrm{TiO}_{2}\right)$, is currently one of the leading sorbents. Overall chemical reactions with $\mathrm{Zn}_{2} \mathrm{TiO}_{4}$ during the desulfurization (sulfidation)-regeneration cycle are shown below:

Sulfidation: $\quad \mathrm{Zn}_{2} \mathrm{TiO}_{4}+2 \mathrm{H}_{2} \mathrm{~S} \rightarrow 2 \mathrm{ZnS}+\mathrm{TiO}_{2}+2 \mathrm{H}_{2} \mathrm{O}$

Regeneration: $2 \mathrm{ZnS}+\mathrm{TiO}_{2}+3 \mathrm{O}_{2} \rightarrow \mathrm{Zn}_{2} \mathrm{TiO}_{4}+2 \mathrm{SO}_{2}$

The sulfidation/regeneration cycle can be carried out in a fixed-bed, moving-bed, or fluidized-bed reactor configuration. The fluidized-bed reactor configuration is most attractive because of several potential advantages including faster kinetics and the ability to handle the highly exothermic regeneration to produce a regeneration offgas containing a constant concentration of $\mathrm{SO}_{2}$.

The $\mathrm{SO}_{2}$ in the regeneration offgas needs to be disposed of in an environmentally acceptable manner. Options for disposal include conversion to a solid 
calcium-based waste using dolomite or limestone, conversion to sulfuric acid, and conversion to elemental sulfur. Elemental sulfur recovery is the most attractive option because sulfur can be easily transported, sold, stọred, or disposed of. However, elemental sulfur recovery using conventional methods is a fairly complex, expensive process. An efficient, cost-effective method is needed to convert the $\mathrm{SO}_{2}$ in the regenerator offgas directly to elemental sulfur.

Research Triangle Institute (RTI) with DOE/FETC sponsorship has been developing zinc titanate sorbent technology since 1986. In addition, RTI has been developing the Direct Sulfur Recovery Process (DSRP) with DOE/FETC sponsorship since 1988. Fluidized-bed zinc titanate desulfurization coupled to the DSRP is currently an advanced, attractive technology for sulfur removal/recovery for IGCC systems.

Under other contracts, RTI (with the help of commercial manufacturers) has developed durable fluidized-bed zinc titanate sorbents that showed excellent durability and reactivity over 100 cycles of testing at up to $750^{\circ} \mathrm{C}$. In bench-scale development tests, zinc titanate sorbent EXSO3 (developed by Intercat and RTI) consistently reduced the $\mathrm{H}_{2} \mathrm{~S}$ in simulated coal gas to $<20 \mathrm{ppmv}$ and demonstrated attrition resistance comparable to fluid catalytic cracking (FCC) catalysts. The sorbent was manufactured by a commercially scalable spray drying technique using commercial equipment. Previous RTI zinc titanate formulations, such as $Z T-4$, have been tested independently by the Institute of Gas Technology (IGT) for Enviropower/Tampella Power, and by others such as British Coal and Ciemat, and showed no reduction in reactivity and capacity after 10 cycles of testing at $650^{\circ} \mathrm{C}$. 
In the DSRP, $\mathrm{SO}_{2}$ is catalytically reduced to elemental sulfur using a small slip stream of the coal gas at the pressure and temperature conditions of the regenerator offgas. A near-stoichiometric mixture of offgas and raw coal gas (2 to $1 \mathrm{~mol}$ ratio of reducing gas to $\mathrm{SO}_{2}$ ) reacts in the presence of a selective catalyst to produce elemental sulfur directly:

$$
\begin{aligned}
& 2 \mathrm{H}_{2}+\mathrm{SO}_{2} \rightarrow(1 / n) \mathrm{S}_{n}+2 \mathrm{H}_{2} \mathrm{O} \\
& 2 \mathrm{CO}+\mathrm{SO}_{2} \rightarrow(1 / n) \mathrm{S}_{n}+2 \mathrm{CO}_{2} \\
& \mathrm{CO}+\mathrm{H}_{2} \mathrm{O} \rightarrow \mathrm{CO}_{2}+\mathrm{H}_{2}
\end{aligned}
$$

The above reactions occur in Stage I of the two-stage (as originally conceived) process, and convert up to $96 \%$ of the inlet $\mathrm{SO}_{2}$ to elemental sulfur. The sulfur is recovered by cooling the outlet gas to condense out the sulfur as a molten solid. All of the $\mathrm{H}_{2}$ and $\mathrm{CO}$ is consumed in the first reactor, with some $\mathrm{H}_{2} \mathrm{~S}$ and $\mathrm{COS}$ forming according to the following reactions:

$$
\begin{aligned}
& 3 \mathrm{H}_{2}+\mathrm{SO}_{2} \rightarrow \mathrm{H}_{2} \mathrm{~S}+2 \mathrm{H}_{2} \mathrm{O} \\
& 3 \mathrm{CO}+\mathrm{SO}_{2} \rightarrow \mathrm{COS}+2 \mathrm{CO}_{2}
\end{aligned}
$$

Adjusting the stoichiometric ratio of coal gas to regenerator offgas to 2 at the inlet of the first reactor also controls the Stage I effluent stoichiometry since any $\mathrm{H}_{2} \mathrm{~S}$ and COS produced by the reactions above yields an $\left(\mathrm{H}_{2} \mathrm{~S}+\mathrm{COS}\right)$ to unconverted $\mathrm{SO}_{2}$ ratio of 2 to 1 . The effluent stoichiometry plays an important role in the Stage II DSRP reactor (operated at 275 to $300^{\circ} \mathrm{C}$ ), where $80 \%$ to $90 \%$ of the remaining sulfur species is converted to elemental sulfur, most probably via these reactions:

$$
\begin{aligned}
& \mathrm{COS}+\mathrm{H}_{2} \mathrm{O} \rightarrow \mathrm{H}_{2} \mathrm{~S}+\mathrm{CO}_{2} \\
& 2 \mathrm{H}_{2} \mathrm{~S}+\mathrm{SO}_{2} \rightarrow(3 / n) \mathrm{S}_{n}+2 \mathrm{H}_{2} \mathrm{O}
\end{aligned}
$$


The prior laboratory work suggested that the overall sulfur recovery could be projected to be $99.5 \%$.

At the start of the current project, the DSRP technology was at the bench-scale development stage with a skid-mounted system ready for field testing. The process had been extended to fluidized-bed operation in the Stage I reactor. Fluidized-bed operation proved to be very successful with conversions up to $94 \%$ at space velocities ranging from 8,000 to $15,000 \mathrm{scc} / \mathrm{cc} \cdot \mathrm{h}$ and fluidizing velocities ranging from 3 to $7 \mathrm{~cm} / \mathrm{s}$. Overall conversion in the two stages following interstage sulfur and water removal had ranged up to $99 \%$.

A preliminary economic study for a $100 \mathrm{MW}$ plant in which the two-stage DSRP was compared to conventional processes indicated the economic attractiveness of the DSRP. For $1 \%$ to $3 \%$ sulfur coals, the installation costs ranged from 25 to $40 \$ / \mathrm{kW}$ and the operating costs ranged from 1.5 to $2.7 \mathrm{mil} / \mathrm{kWh}$.

Through bench-scale development, both fluidized-bed zinc titanate and DSRP technologies have been shown to be technically and economically attractive. The demonstrations prior to the start of this project, however, had only been conducted using simulated (rather than real) coal gas and simulated regeneration off-gas. Thus, the effect of trace contaminants in real coal gases on the sorbent and DSRP catalyst was not known. Also, the zinc titanate desulfurization unit and DSRP had not been demonstrated in an integrated manner.

The overall goal of this project is to continue further development of the zinc titanate desulfurization and DSRP technologies by scale-up and field testing (with actual coal gas) of the zinc titanate fluidized-bed reactor system, and the Direct Sulfur 
Recovery Process.

By the end of the 1996 Fiscal Year, the following milestones had been achieved toward that goal:

- Construction of a larger, skid-mounted zinc titanate fluidized-bed desulfurization (ZTFBD) reactor system;

- Integration of the ZTFBD with the skid-mounted DSRP and installation of these process units into a specially-equipped office trailer to form a Mobile Laboratory;

- Transport to and installation of the ZTFBD/DSRP Mobile Laboratory at the FETC Morgantown site for testing with a slip stream of actual coal gas from the pilot gasifier located there;

- $\quad$ Shake-down and testing of the ZT-4 sorbent integrated with the 2-stage DSRP during September and October 1994;

- Discovery that in longer duration testing, the second stage of the DSRP did not aid overall conversion of the inlet $\mathrm{SO}_{2}$ to elemental sulfur, and subsequent modification to the DSRP process equipment;

- Additional, longer duration $(160 \mathrm{~h})$ testing of the simplified, single-stage DSRP during July, 1995, and determination of no degradative effect of the trace contaminants present in coal gas over this time period;

- Exposure of the used DSRP catalyst to an additional $200 \mathrm{~h}$ of coal gas at the General Electric pilot plant gasifier, and subsequent testing of the exposed catalyst in a bench-scale DSRP in the RTI laboratory; and,

- Design and partial construction of six-fold larger ("6X"), single-stage DSRP process unit intended for additional field testing.

The plans for additional work in this project (in Fiscal Year 1997 and beyond) include the following:

- $\quad$ Additional long duration exposure of the DSRP catalyst to actual coal gas from the Kellogg-Rust-Westinghouse (KRW) gasifier at FETC's Power Systems Development Facility (PSDF) in Wilsonville, Alabama, and subsequent testing in RTI's bench-scale DSRP; 
- Additional development of the fluidized-bed DSRP to handle high concentrations (up to $14 \%$ ) of $\mathrm{SO}_{2}$ that are likely to be encountered when pure air is used for regeneration of desulfurization sorbents;

- Modification of the ZTFBD/DSRP Mobile Laboratory for use as a portable control and analyzer room for the 6X DSRP;

- Completion of construction of the 6X DSRP process equipment in preparation for field testing; and

- Extended duration field testing of the 6X DSRP at PSDF with actual coal gas and high concentrations of $\mathrm{SO}_{2}$. 


\subsection{TECHNICAL DISCUSSION}

\subsection{EXPOSURE TEST AT PSDF}

No work was conducted on this task during this reporting period.

\subsection{BENCH-SCALE FLUID-BED TESTING WITH HIGH-SO $\mathrm{S}_{2}$ CONCENTRATION FEED STREAMS}

No work was conducted on this task during this reporting period.

\subsection{SLIPSTREAM TESTING OF THE 6X DSRP UNIT AT PSDF}

\subsubsection{Project Planning}

The piping and instrumentation diagrams (P\&IDs) for the RTI self-contained process and analytical equipment were essentially completed. Small modifications will likely continue to be made to the drawings in order to document "as-built" configuration, and to incorporate design changes made during the final assembly. However, the basic plans are now sufficiently complete that final fabrication of the skid-mounted DSRP unit, the control panel, and the analytical instrumentation inside the Mobile Laboratory can proceed in earnest.

It should be pointed out that the design is complete only for the "self-contained" portion of the process - that is, the portion of the RTI scope of work that is inside the trailer or is fully on the skid. The design of the interface of the RTI process with the PSDF process and utility lines is not complete. The subcontract between RTI and Southern Company Services (SCS) is not in place, and no liaison staff has been 
assigned by SCS to assist with the details of the process interface.

The mechanical designs are complete for the several equipment items that were redesigned or had to be added to the RTI scope when the test site was identified to be the PSDF:

- the simulated regeneration off-gas (Sim ROG) preheater coil and furnace;

- the re-designed reactor vessel (to incorporate fluid-bed, as well as fixedbed testing);

- the sulfur separator pot; and,

- the sulfur collection canister (not previously part of the RTI scope).

It is anticipated that one of the tasks that RTI will be required to do in order to have the process equipment approved by SCS for operation at PSDF will be to conduct process hazard analysis (safety review) following the HAZOP protocol. The potential purchase of facilitating software is being evaluated.

The operative schedule is currently estimated to call for the RTI equipment to move to Wilsonville, AL, in November of this calendar year, and to be fully hooked up and ready for slip-stream testing starting after January 2000. This schedule represents a small slippage from that described in the previous quarterly technical progress report.

\subsubsection{Equipment Acquisition}

The order was placed for the stand-alone control panel that will be required for remote control of the skid-mounted DSRP Unit. The control panel will use a programmable logic controller (PLC) to provide the control and process interlock logic. The operator interface will be a personal computer running National Instruments 
"Lookout" commercial software for supervisory control and data acquisition (SCADA) and will included data logging and trending. The control panel and SCADA computer will be located inside the Mobile Laboratory.

The original process control plan called for the use of a free-standing hydrogen analyzer that would function utilizing the thermal conductivity principle of measurement. As the project work has proceeded, and the design of the process control system has firmed up, there was a chance to fully investigate the specifics of the gas analysis problem; it was determined that a thermal conductivity analyzer would not be sufficiently accurate for this application. Rather, a gas chromatograph (GC) should be used to make the hydrogen measurement. A arrangement has been designed whereby an existing Carle $400 \mathrm{GC}$ (specially equipped to analyze for hydrogen) will be interfaced to the DSRP process control system by using a PC running special chromatography software. Purchase of the required software has been initiated.

\subsubsection{Fabrication/Construction}

Construction activities during this quarter centered mostly on the configuration of the equipment skid. An extension was fabricated for the process equipment skid in order to support the heater control panel immediately adjacent to the process equipment. The process equipment skid and the heater control skid extension were both mounted on and welded to a supporting underframe in order to form a single, contiguous equipment skid. Figure 1 shows the new, large skid under construction. 


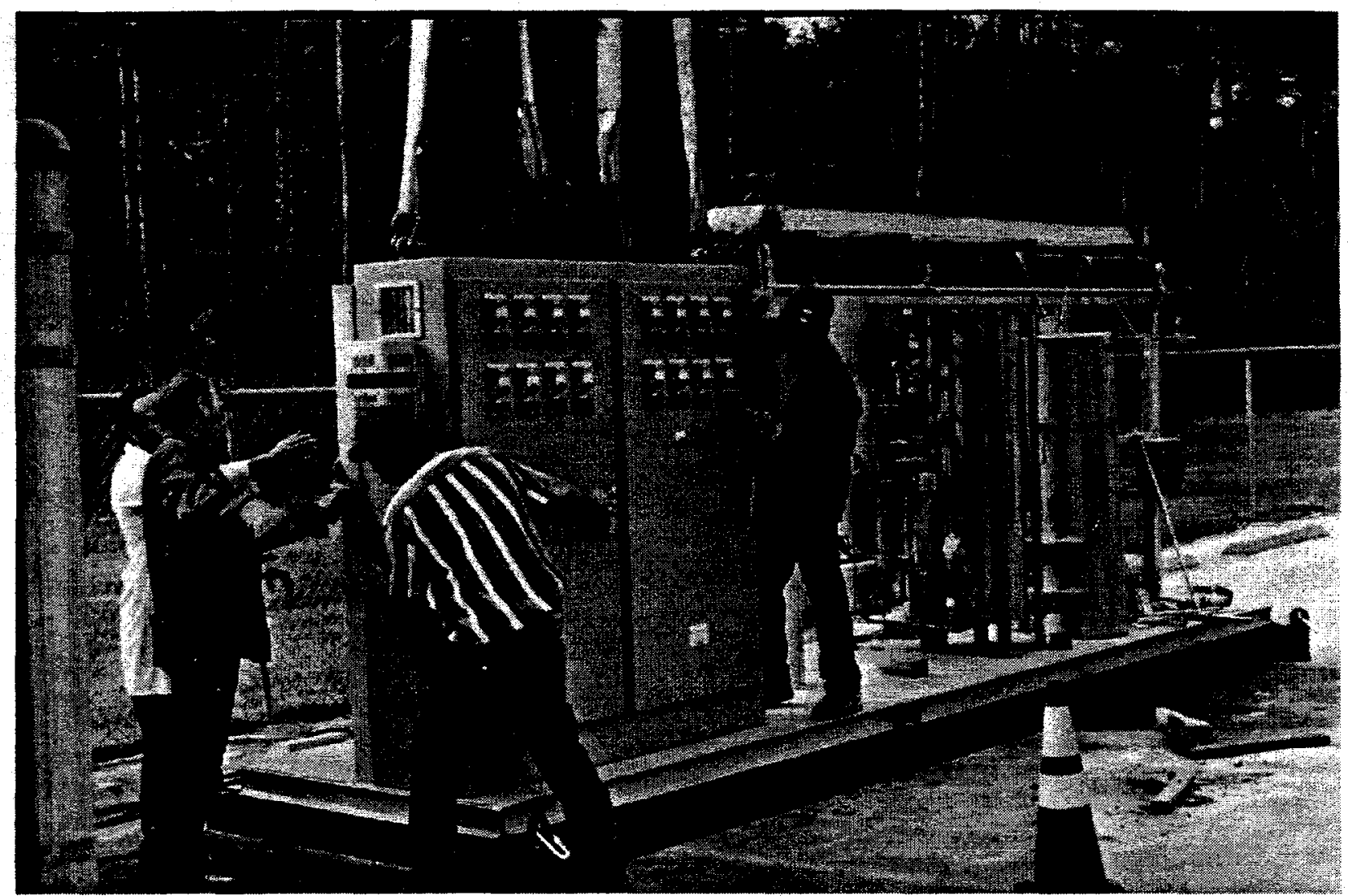

Figure 1. Heater control panel being positioned on newly-enlarged frame of SkidMounted DSRP Unit. 


\subsection{PLANS FOR NEXT QUARTER}

The following activities are planned for the next quarter:

- Continue the construction activities associated with the modification and renovation of the control room in the Mobile Laboratory.

- Conduct a hazard and operability analysis (HAZOP) of the RTI-supplied equipment, based on the piping and instrumentation diagrams (P\&ID's) prepared, as part of the previous task noted above. Revise the equipment design and control system, as required.

- Provide technical support, as needed, to the RTI Office of Research Contracts so that the subcontract with Southern Company Services can be put in place.

- Fabricate the redesigned reactor vessel, sulfur separator pot, and sulfur collection canister.

- Purchase and install a carport to cover the enlarged DSRP equipment skid while it is temporarily located outside the RTI shop.

- Install the redesigned reactor vessel, sulfur separator pot, and sulfur collection canister on the equipment skid.

- Develop the specifications and place the order for the additional heater (furnace) required for the Sim ROG system.

- $\quad$ Prepare the engineering design and purchase specifications for the custom-designed heat tracing elements. 